\title{
POLÍTICAS DE EDUCAÇÃO INTEGRAL: CONTRIBUIÇÕES DO CICLO DA POLÍTICA BALL
}

\author{
Maria do Amparo Oliveira Brito* \\ Milena da Trindade Gomes*
}

\section{RESUMO}

O presente estudo é resultado de uma pesquisa realizada no Programa de Mestrado com o intuito de discutir sobre os percursos e rumos do Ensino Médio e o processo de implementação do Programa Ensino Médio Inovador em uma escola estadual do estado da Bahia. Buscou-se, investigar quais as transformações ocorridas na escola com a implementação do referido Programa. Neste contexto esta pesquisa busca compreender como a política curricular do PROEMI é recontextualizada do contexto da influência ao contexto da prática, além disso, como esta proposta tem influenciado as práticas pedagógicas na referida instituição de ensino. Para tanto, a pesquisa baseia-se no referencial teórico de Ball e Mainardes (2011), Ball, Maguire e Braun (2016), Lopes (2005) e Mainardes (2006), com enfoque nas políticas educacionais. A final deste trabalho ficou perceptível que os processos de recontextualização do PROEMI ocorrem de maneiras a garantir a ampliação do tempo de permanência dos alunos na escola e a participação nos projetos estruturantes da Secretaria da Educação. A pesquisa sinaliza ainda como resultado que os impactos dessa política podem ser percebidos na melhoria do desempenho dos alunos em avaliações externas, assim como no aumento dos indicadores educacionais, a exemplo do IDEB. No entanto, evidenciou-se que há um engessamento da proposta, na medida em que o redesenho do currículo escolar abarca apenas um modelo de atividade pedagógica: a oficina.

Palavras-chave: PROEMI. Educação Integral. Ciclo de Políticas. Currículo. Políticas Públicas.

\footnotetext{
* Mestranda em Educação pela Facultad Interamericana de Ciencias Sociales. Asunción-PY. Contatos: E-mail: amparocba@yahoo.com (77) 98115-4741

* Mestranda em Educação pela Facultad Interamericana de Ciencias Sociales. Asunción-PY. E-mail: amparocba@yahoo.com.br. Telefone: (77) 98115-4741.
} 


\section{INTRODUÇÃO}

Este trabalho é um recorte dos resultados de uma pesquisa de mestrado que buscou compreender a recontextualização do PROEMI em um colégio estadual do Sudoeste da Bahia. Para tanto, buscou-se apreender as contribuições do Ciclo de Política de Ball como fomentador da educação integral do contexto da influencia ao contexto da prática dos professores de uma escola estadual no interior da Bahia.

O PROEMI se apresenta como estratégia do MEC para melhorar a qualidade do Ensino Médio por meio da dinamização e flexibilização do currículo. Neste contexto este trabalho buscou, investigar quais as transformações ocorridas na escola com a implementação do referido Programa, além disso, compreender como a política curricular do PROEMI é recontextualizada do contexto da influência ao contexto da prática, e como esta proposta tem influenciado as práticas pedagógicas na referida instituição de ensino. Para tanto dividimos este trabalho em quatro capítulos.

Destarte, a pesquisa baseia-se no referencial teórico de Ball e Mainardes (2011), Ball, Maguire e Braun (2016), Lopes (2005) e Mainardes (2006), com enfoque nas políticas educacionais.

A opção pela análise dos processos de recontextualização pauta-se em Bernstein (1996) e Lopes (2008), fundamentou no ciclo de política de Ball (2001, 2006) e, por fim, Bardin (1979, 2011) imprimiu a partir da análise da enunciação os métodos de compreensão dos dados coletados.

Ao final da pesquisa, ficou perceptível que os processos de recontextualização do PROEMI ocorrem de maneiras a garantir a ampliação do tempo de permanência dos alunos na escola e a participação nos projetos estruturantes da Secretaria da Educação. A pesquisa sinaliza ainda como resultado que os impactos dessa política podem ser percebidos na melhoria do desempenho dos alunos em avaliações externas, assim como no aumento dos indicadores educacionais, a exemplo do IDEB e ENEM. No entanto, evidenciou-se que há um engessamento da proposta, na medida em que o redesenho do currículo escolar abarca apenas um modelo de atividade pedagógica: a oficina. 


\section{SURGIMENTO DO PROEMI}

Com o objetivo de traçar um panorama da situação do Ensino Médio no Brasil foi criado um Grupo de Trabalho - GT Interministerial entre o Ministério da Educação - MEC e a Secretaria de Assuntos Estratégicos da Presidência da Republica (SAE) por meio da Portaria ${ }^{\circ}$ 1189, de 05 de dezembro de 2007, e a Portaria nº. 386, de 25 de março de 2008.

O GT Interministerial elaborou o documento "Reestruturação e Expansão do Ensino Médio no Brasil, que além de mapear os desafios vivenciados pela Educação Básica no país e em especial o Ensino Médio, propõe elementos e pressupostos para uma política para essa modalidade de ensino, que visa atender aos jovens na faixa etária ente os 15 e 17 anos.

A universalização dessa etapa da educação básica deverá elevar a escolaridade dos jovens, garantindo uma educação de qualidade, e consequentemente promover melhorias em sua condição de vida. Expressa nos seguintes princípios elencados no documento:

- $\quad$ Obrigatoriedade do Ensino Médio no Brasil;

- $\quad$ O Ensino Médio - etapa final da educação básica - objetiva a autonomia do educando frente às determinações do mercado de trabalho;

- $\mathrm{O}$ processo educativo está centrado nos sujeitos da aprendizagem, sejam jovens ou adultos, respeitadas suas características biopsicológicas, sócio-culturais e econômicas;

- As condições para o exercício da docência são garantidas pelo fortalecimento da identidade e profissionalidade docente e da centralidade de sua ação no processo educativo;

- $\quad$ A identidade do Ensino Médio, como etapa final da educação básica, deve ser construída com base em uma concepção curricular cujo principio é a unidade entre trabalho, ciência, cultura e tecnologia;

- $\quad$ O Ensino Médio integrado à educação profissional técnica é atualmente uma das mais importantes políticas públicas, mas parcial para a concretização da identidade do Ensino Médio brasileiro;

- $\quad$ A União tem como responsabilidade a coordenação nacional das políticas públicas para o Ensino Médio, em regime de colaboração com as unidades federadas. (Brasil, MEC/SAE, 2008) 
Apesar de avanços oriundos na educação como o da ampliação da matrícula no ensino básico existia lacunas que precisavam ser revertidas como a permanência na escola e a aprendizagem dos estudantes. Diante do estudo realizado o GT Interministerial traçou-se os objetivos estratégicos:

Fortalecer a política pública para o ensino médio na articulação com o PNE e PDE e a coordenação nacional do MEC; Consolidar a identidade unitária do ensino médio como etapa final da educação básica considerando a diversidade dos sujeitos e, em particular, as questões da profissionalização, da educação no campo e da EJA; Desenvolver e reestruturar o currículo do ensino médio em torno da ciência, da cultura e do trabalho; Valorizar os profissionais da educação do ensino médio; Priorizar os sujeitos jovens e os adultos estudantes do ensino médio; Melhorar a qualidade do ensino médio nas escolas públicas estaduais; Expandir a oferta do ensino médio nas escolas federais em articulação com a rede estadual. (Brasil, MEC/SAE, 2008, p.10)

No entanto as recomendações do GT Interministerial precisariam ser discutidas por vários órgãos do MEC, como SECAD, SETEC e SEB e servir como base para subsidiar a formulação da política, de maneira articulada entre estas secretarias. $\mathrm{O}$ documento elaborado não constituía uma política pública educacional, era apenas um levantamento de diagnóstico e uma proposta (ISLEB, 2016).

A proposta de inovação curricular fora encaminhada ao Conselho Nacional de Educação - CNE em fevereiro de 2009 pela Secretaria de Educação básica SEB/MEC, após ampla discussão dos problemas enfrentados pelo ensino médio no Brasil.

Neste contexto o Parecer CNE/CP N $11 / 2009$ foi aprovado em 30/06/2009 e publicado no Diário Oficial da União de 25/08/2009. As pesquisas divulgadas nesse período abordavam que apesar de ter 12 anos de nova LDB, os resultados ainda não garantiam a permanência e aprendizagem dos jovens nesse nível de ensino, onde $90 \%$ das matriculas era no ensino médio não profissionalizante.

Como proposta inovadora o programa de inovações curriculares busca aliar ações já desenvolvidas pelo Governo Federal em parceria com os estados e municípios estabelecidas no Plano de Metas do Decreto no 6.094 de 24/04/2007, que visa a melhoria do Ensino Médio público, propondo a superação das desigualdades de oportunidades educacionais; universalização do acesso e permanência dos adolescentes de 15 a 17 anos no Ensino Médio; consolidação da identidade desta etapa educacional e oferta de aprendizagem significativa para jovens e adultos.

Nesse aspecto Saviani (2005) afirma que: 
[...] o enfrentamento dos desafios postos à educação pública pela sociedade de classes passa, do ponto de vista da pedagogia histórico-crítica, pela luta por uma escola pública que garanta aos trabalhadores um ensino da melhor qualidade possível nas condições históricas atuais, entendida como um componente na luta mais ampla pela superação da própria sociedade de classes. (SAVIANI, 2005, p.271).

O Ensino Médio, enquanto etapa intermediária entre o Ensino Fundamental e o Ensino Superior vive uma dicotomia ente propedêutico e profissionalizante apresentada na Lei de Diretrizes e Bases da Educação - LDB 9394/96 em seu art. 35, incisos I e II, entre as finalidades do ensino médio, a consolidação e o aprofundamento dos conhecimentos adquiridos no ensino fundamental possibilitando o prosseguimento dos estudos, e a preparação básica para o trabalho e a cidadania do educando para continuar aprendendo, de modo a ser capaz de se adaptar com flexibilidade às novas condições de ocupação posteriores.

Diante dessa contradição, Saviani (2005) propõe que:

O desenvolvimento da educação e, especificamente, da escola pública, entra em contradição com as exigências inerentes à sociedade de classes de tipo capitalista. Esta ao mesmo tempo em que exige a universalização da forma escolar de educação, não a pode realizar plenamente, porque isso implicaria a sua própria superação. (SAVIANI, 2005, p.257).

Com índices de evasão, reprovação e distorção idade/série elevados no Ensino Médio, o Ministério da Educação (MEC) planeja intervenções para este nível de ensino, com o objetivo de melhorar o desempenho nos aspectos quantitativos como nos aspectos qualitativos desta etapa da educação brasileira, criando o PROEMI - Programa Ensino Médio Inovador.

\subsection{Objetivos do PROEMI}

O PROEMI foi instituído pela Portaria $n^{\text {o }} 971$ de 09/10/2009 e tem o objetivo de incentivar o desenvolvimento de políticas educacionais, a fim de fomentar mudanças curriculares e ações junto as Secretarias de Estado da Educação.

Conforme estabelece o Art. $2^{\circ}$ : O Programa visa apoiar as Secretarias Estaduais de Educação e do Distrito Federal no desenvolvimento de ações de melhoria da qualidade do ensino médio não profissionalizante, com ênfase nos projetos pedagógicos que promovam a educação científica e humanística, a valorização da leitura, da cultura, o aprimoramento da relação teoria e prática, da utilização de novas tecnologias e o desenvolvimento de metodologias criativas e emancipadoras (BRASIL, MEC 2009).

Para a execução do que propõe a artigo $2^{\circ}$ foram estabelecidos os seguintes objetivos:

- $\quad$ I - expandir o atendimento e melhorar a qualidade do ensino médio; 
- $\quad$ II - desenvolver e reestruturar o ensino médio não profissionalizante, de forma a combinar formação geral, científica, tecnológica, cultural e conhecimentos técnico-experimentais;

- $\quad$ III - promover e estimular a inovação curricular no ensino médio;

- $\quad$ IV - incentivar o retorno de adolescentes e jovens ao sistema escolar e proporcionar a elevação da escolaridade;

- V V - fomentar o diálogo entre a escola e os sujeitos adolescentes e jovens;

- VI - promover uma escola média onde os saberes e conhecimentos tenham significado para os estudantes e desenvolvem sua autonomia intelectual;

- $\quad$ VII - desenvolver a autonomia do estudante por meio do oferecimento de uma aprendizagem significativa.

- $\quad$ VIII - criar uma rede nacional de escolas de ensino médio públicas e privadas que possibilite o intercâmbio de projetos pedagógicas inovadores.

- IX - promover o intercâmbio dos Colégios de Aplicação das IFES, dos Institutos Federais e do Colégio Pedro II com as redes públicas estaduais de ensino médio.

- $\quad \mathrm{X}$ - incentivar a articulação, por meio de parcerias, do Sistema S com as redes públicas de ensino médio estaduais.

Para assegurar a execução desses objetivos o Ministério da Educação disponibilizaria apoio técnico e financeiro aos estados através da descentralização de recursos para as secretarias estaduais visando a operacionalização do programa. Ficando a cargo da Secretaria da Educação Básica, órgão ligado ao MEC, a responsabilidade de implantar, acompanhar, monitorar, supervisionar e avaliar o Programa.

\subsection{Projeto de Redesenho Curricular para atender os macrocampos}

O Programa Ensino Médio Inovador faz parte das ações previstas no Plano de Desenvolvimento da Educação (PDE), para implementar o redesenho dos currículos do Ensino Médio.

O Ministério da Educação propõe a ampliação da jornada escolar contemplando a diversificação das práticas pedagógicas. As atividades diferenciadas são incorporadas ao currículo gradativamente de acordo com os macrocampos definidos pela equipe escolar. 
Para implementar o currículo da escola, o Programa estabelece,que o Projeto de Redesenho Curricular - PRC contemple ações que articulam as dimensões do trabalho, da ciência, da cultura e da tecnologia como eixos estruturantes na formação dos jovens dessa etapa da educação básica.

O Documento Orientador (2014) propõe que a escola desenvolva ações considerando os eixos estruturantes, sendo que:

\begin{abstract}
Não se trata, assim, de oferecer atividades ora ligadas ao trabalho, ora à cultura ou à ciência ou à tecnologia. O que se está propondo é que todo o currículo do ensino médio se organize a partir de um eixo comum - trabalho, ciência, tecnologia e cultura - e que se integre, a partir desse eixo o conjunto dos conhecimentos, seja quando se tratar das disciplinas, seja em outras formas de organização do trabalho pedagógico. $\mathrm{O}$ currículo integrado em torno do eixo trabalho-ciência-tecnologia-cultura e com foco nas áreas de conhecimento será capaz de atribuir novos sentidos à escola, dinamizar as experiências oferecidas aos jovens estudantes, re-significar os saberes e experiências (BRASIL, MEC/SEB, 2014, p.9)
\end{abstract}

Com a ampliação da jornada escolar é possível construir um currículo mais atrativo aos jovens oportunizando a realização de ações e atividades a partir de um planejamento interdisciplinar, discutido coletivamente, onde o percurso formativo valorize os tempos e espaços dos sujeitos, proporcionando assim a formação integral.

Segundo o Ministério da Educação, o PROEMI é um compromisso assumido pelos governos federal em parceria com o Distrito Federal e os estados para assegurar a ampliação da jornada escolar de no mínimo carga horária de 3000 horas anualmente, distribuídas entre 2400 horas de atividades obrigatórias e 600 horas acrescidas de forma gradativa.

Além disso, a escola selecionada deverá apresentar através da respectiva Secretaria de Educação um Plano de Ação Pedagógica (PAP) contendo o compromisso de assegurar o cumprimento das metas estabelecidas. Considerando os seguintes indicativos:

Contemplar atividades integradoras de iniciação científica e no campo artístico-cultural;

Incorporar, como princípio educativo, a metodologia da problematização como instrumento de incentivo à pesquisa, à curiosidade pelo inusitado e ao desenvolvimento do espírito inventivo, nas práticas didáticas;

Promover a aprendizagem criativa por um processo de sistematização dos conhecimentos elaborados, como caminho pedagógico de superação à mera memorização; 
$>\quad$ Promover a valorização da leitura em todos os campos do saber, desenvolvendo a capacidade de letramento dos alunos;

Fomentar o comportamento ético, como ponto de partida para o reconhecimento dos deveres e direitos da cidadania; praticando um humanismo contemporâneo, pelo reconhecimento, respeito e acolhimento da identidade do outro e pela incorporação da solidariedade;

$>$ Articular teoria e prática, vinculando o trabalho intelectual com atividades práticas experimentais;

$>$ Utilizar novas mídias e tecnologias educacionais, como processos de dinamização dos ambientes de aprendizagem;

Estimular a capacidade de aprender do aluno, desenvolvendo o autodidatismo e autonomia dos estudantes;

Promover atividades sociais que estimulem o convívio humano e interativo do mundo dos jovens;

$>\quad$ Promover a integração com o mundo do trabalho por meio de estágios direcionados para os estudantes do ensino médio;

Organizar os tempos e os espaços com ações efetivas de interdisciplinaridade e contextualização dos conhecimentos;

Garantir o acompanhamento da vida escolar dos estudantes, desde o diagnóstico preliminar, com acompanhamento do desempenho e integração com a família;

$>\quad$ Ofertar atividades complementares e de reforço da aprendizagem, como meio para elevação das bases para que o aluno tenha sucesso em seus estudos;

$>\quad$ Ofertar atividades de estudo com utilização de novas tecnologias de comunicação;

Avaliação da aprendizagem como processo formativo e permanente de reconhecimento de saberes, competências, habilidades e atitudes;

$>$ Reconhecer as diferentes facetas da exclusão na sociedade brasileira, para assegurar a ampliação do acesso aos sujeitos historicamente excluídos do Ensino Médio;

Garantir a inclusão das temáticas que valorizem os direitos humanos e contribuam para o enfrentamento do preconceito, da discriminação e da violência no interior das escolas; 
$>$ Desenvolver a compreensão da realidade brasileira, de sua organização social e produtiva na relação de complementaridade entre espaços urbanos e rurais;

Valorizar o estudo e as atividades socioambientais e projetos de extensão;

Desenvolver conhecimentos e habilidades associados a aspectos comportamentais (relacionamento, comunicação, iniciativa, cooperação, compromisso), relativos às atividades de gestão e de iniciativas empreendedoras;

Valorizar práticas desportivas e de expressão corporal, referidas à saúde, à sociabilidade e à cooperação; e

$>$ Estimular a participação social dos jovens, como agentes de transformação de suas escolas e de suas comunidades.

Para a operacionalização do PROEMI as atividades propostas devem estar articuladas aos componentes curriculares, tendo como referências os objetivos constantes no Projeto Político Pedagógico da escola. Essas atividades didático-pedagógicas estão inseridas nas diversas áreas de conhecimento percebidas como grandes campos de ação educacional e interativa denominadas de macrocampos (BAHIA 2015).

O Documento Base do Ensino Médio Inovador apresenta como objetivo inicial:

\footnotetext{
Estabelecer mudanças significativas nas escolas públicas de ensino médio, não profissionalizante, no país, revertendo os dados relativos a esta etapa da educação básica [...] reconhecendo a importância do estabelecimento de uma nova organização curricular, que possa fomentar as bases para uma nova escola de ensino médio ((BRASIL, 2009 p. 16).
}

As ações previstas no PRC poderão ser estruturadas em vários formatos como oficinas, disciplinas optativas, seminários integrados, grupos de pesquisas, trabalhos de campo e demais ações interdisciplinares. Tendo como princípio os interesses e necessidades da equipe escolar preponderando o interesse dos alunos do ensino médio.

Uma das proposições para a construção do redesenho curricular do programa, é conforme o Documento Orientador de 2014, "a oferta de ações que poderão estar estruturadas em práticas pedagógicas multi ou interdisciplinares articulando conteúdos de diferentes componentes curriculares de uma ou mais áreas do conhecimento”.(BRASIL, 2014, p. 5).

\section{CIClO de POLÍTICA: UMA CONTRIBUiÇÃo PARA ANÁliSE DO PROEMI COMO INDUTOR DA EDUCAÇÃO INTEGRAL}


Para compreender como as políticas de Educação Integral são desenvolvidas do contexto da influência ao contexto da prática, utilizamos para subsidiar nossa análise o ciclo de políticas de Bowe e Ball (1992), o qual considera que a maior parte das políticas "são frágeis, produto de acordos, algo que pode ou não funcionar; elas são retrabalhadas, aperfeiçoadas, ensaiadas, crivadas de nuances e moduladas através de complexos processos de influência, produção e disseminação de textos e, em última análise, recriadas nos contextos da prática" (BALL, 2001, p. 102).

Sendo assim, a partir da Abordagem do Ciclo de Políticas, analisamos os contextos do PROEMI política indutora da Educação Integral, vem sendo produzido e traduzido em uma escola estadual do sudoeste baiano.

Utilizaremos os ensinamentos de Ball (1992) que defende a existência de três contextos cada um deles com diversas arenas de ação. Esses contextos situam-se em um ciclo contínuo de políticas e podem ser definidos como: Contexto de influência, em que normalmente as definições políticas são iniciadas e os discursos políticos são construídos; nele acontecem as disputas entre quem influencia a definição das finalidades sociais da educação e do que significa ser educado.

Atuam nesse contexto as redes sociais dentro e em torno dos partidos políticos, do governo, do processo legislativo, das agências multilaterais, dos governos de outros países cujas políticas são referência para o país em questão; Contexto de produção dos textos das definições políticas, o poder central propriamente dito, que mantém uma associação estreita com o primeiro contexto; e o Contexto da prática, onde as definições curriculares são recriadas e reinterpretadas, (LOPES, 2004).

O ciclo de políticas de Bowe e Ball (1992) e os estudos de Ball (1997, 1998) nos proporcionam compreender as concepções de política curricular como recurso político em construção, perceptível de traduções e, consequentemente, recriação, superando a ideia de hierarquização das políticas, criadas em uma instância estatal cabendo à escola apenas o papel de implementação ou de resistência (LOPES, 2006).

Para tanto, realizamos uma análise da trajetória de programas e políticas no campo da educação integral desde sua formulação inicial até a implementação no contexto da prática e seus efeitos. 
Para Mainardes (2006) o foco da análise das políticas deveria incidir sobre a formação de seu próprio discurso e sobre a interpretação - tradução ativa - que os profissionais que atuam no contexto da prática fazem para relacionar os textos da política à prática. Essa interpretação permite identificar processos de resistência, acomodações, pretextos e conformismo dentro e entre as arenas da prática, e o delineamento de conflitos e disparidades entre os discursos nessas arenas.

Neste contexto, os profissionais que atuam nas escolas não são excluídos dos processos de formulação ou implementação das políticas, visto que é na prática no cotidiano escolar que a política que pensada, escrita toma forma e vira modelo.

Neste trabalho, a abordagem do ciclo de políticas auxilia na análise da produção das políticas para a educação integral, na qual inclui a participação de diversos segmentos da sociedade ultrapassando a visão estadocêntrica. Para Ball (2001), as políticas educacionais são expressas em textos e discursos, e devem ser percebidas como indissociáveis, pois uma está submetida à outra.

Essas políticas, muitas vezes, são vinculadas ao currículo e documentos, entendidas como criação de propostas curriculares pelo poder público. Contudo, elas não se apresentam somente em termos de documentos oficiais, ou textos curriculares, mas também se amplificam para além dos limites do poder público e oferecem conotações que são forjadas no corpo social da educação (SANTOS, 2018).

Neste sentido, é questionável o pensamento de que as políticas são implementadas pelo Estado, uma vez que a política educacional não é manipulada apenas verticalmente, de cima para baixo, ela perpassa por um processo de pensamento, construção e prática.

Assim, a abordagem do ciclo de políticas de Bowe e Ball (1992) possibilita realizar a análise da política de educação integral do contexto da influência ao contexto da prática, pois o ciclo de políticas, "permite uma análise crítica e contextualizada de programas e políticas educacionais desde sua formulação até a sua efetivação no contexto da prática, bem como seus resultados/efeitos" (MAINARDES, 2006, p. 48).

A análise, aqui empreendida, parte da compreensão de que as políticas são textos que são interpretados de maneira complexa em meio a muitas compreensões, negociações, convenções e alianças que refletem a própria historicidade. (BALL; BOWE 1992). 
Essa abordagem compreende que as fases de formulação e implementação das políticas não são estanques ou lineares. Os processos políticos sofrem reinterpretações por parte dos sujeitos envolvidos na política (SANTOS, 2018).

Neste trabalho buscamos compreender as interpretações dadas pelos atores que movimentam esta política na prática, por meio dos questionários, professores e gestores puderam atribuir suas impressões sobre a consequência da prática do PROEMI no colégio estudado.

Mainardes (2006) indica a necessidade de articular os processos macro e micro, considerando a ação dos profissionais no nível local. O referido autor salienta que o foco da análise de políticas deveria incidir sobre a formação do discurso da política e sobre a interpretação ativa que os profissionais que atuam no contexto da prática fazem para relacionar os textos da política à prática. (MAINARDES, 2006).

Neste contexto analisamos o sentido e significado do programa Ensino Médio Inovador, como indutor da Educação integral na prática dos educadores e gestores. Além disso, observamos esta política educacional com foco na formação do discurso da política considerando as influências, as disputas e resistências presentes na produção dos textos documentos norteadores de implementação do PROEMI - bem como na ação dos profissionais no microcontexto - professores e equipe gestora.

Para isso, buscamos interpretar e compreender as vozes dos interlocutores envolvidos nas traduções das políticas educacionais, na sua produção e na prática diária da escola, na tentativa de ultrapassar a visão de que as políticas são produzidas pelo Estado e posteriormente implementadas, como se coubesse a escola somente o papel de colocar em prática o que está prescrito nos documentos oficiais.

Ball (1992), salienta a importância das interpretações dos textos da política realizadas pelos profissionais que atuam no contexto da prática. Visto que para analisar o ciclo da política, existe uma dinâmica e inter-relação entre três contextos: o contexto de influência, o contexto da produção do texto e o contexto da prática. Cada um dos contextos apresenta arenas, lugares e grupos de interesse e cada um deles envolve disputas e embates (MAINARDES, 2007).

O referido autor salienta que o contexto de influência é onde os discursos políticos são construídos, havendo disputas de interesse de diferentes grupos com o intuito de influenciar a 
definição das finalidades sociais da educação, além disso, é no contexto de influência que os conceitos adquirem legitimidade e transforma um discurso de base para a política.

Neste sentido, é importante considerar as influências globais e internacionais no processo de formulação das políticas nacionais. Observando como as ideias são recontextualizadas.

Assim, esse autor compreende as políticas como produto de um nexo de influências e interdependências que resultam numa interconexão, e hibridização, isto é, a combinação de lógicas globais, distantes e locais (BALL; BOWE, 1992; BALL, 2006).

Dessa forma, a fim de compreendermos como as políticas de educação integral acontecem na prática, aproveitaremos o conceito de recontextualização de Bernstein (1996), o qual defende que o discurso pedagógico não é um discurso em si, mas é um princípio de recontextualização que se apropria de outros discursos e os realocam de acordo sua própria lógica de ordenamento.

Bernstein (1996) identifica a presença de dois campos recontextualizadores pedagógicos, o oficial e o não oficial. Nesta pesquisa, acessaremos o campo oficial por meio do Documento Orientador do PROEMI, o PPP da escola e o PAP com o objetivo de entendermos como o discurso pedagógico é produzido nos documentos. No campo não oficial (práticas, conteúdos) buscamos entender "o que" está sendo dito, "como" está sendo dito, a forma de transmissão e recontextualização dos documentos oficiais, por meio de entrevista com professores e gestores.

Segundo Ball (1994), o contexto de produção de textos é a arena de produção da política, em que sujeitos disputam por legitimar visões particulares nos documentos. É neste contexto que acontecem as vivências dos textos políticos, emergindo seus efeitos e suas consequências.

Estes textos estão sujeitos a interpretação e recriação, podendo representar mudanças e transformações significativas na política original. Por isso, não acontece, uma simples implementação, visto que aquilo que professores e demais profissionais entendem e imaginam podem ter diversas interpretações que fazem com que essas políticas sejam recriadas na prática. Além disso, as diferentes interpretações também disputam entre si, prevalecendo algumas vozes sobre outras, dependendo de interesses diversos (MAINARDES, 2006). 
Este contexto foi acessado por meio de análise documental. Para tanto, confrontamos as informações dos documentos produzidos para atender as determinações da política de educação integral com os relatos dos profissionais entrevistados.

A investigação do contexto da prática permitiu a apreensão do ciclo de políticas de forma ampla e dinâmica, visto que este contexto se articula intensamente com os demais. A abordagem do ciclo de políticas não percebe a escola como o contexto que tem superioridade em relação aos outros, e muito menos como um contexto que apenas implementa ou responde às ações dos demais contextos.

Para Ball (1994), os discursos e textos que circulam nos contextos de influência e de produção de textos, estão presentes na escola, assim como significados da escola circulam nesses dois contextos.

Neste sentido quando Ball, afirma que os professores podem apresentar suas experiências para a construção/reconstrução do currículo ou não, mostra que isso é um processo social, pessoal e também material, na medida em que as políticas têm de ser "representadas" em contextos materiais como é o caso da escola pesquisada.

Assim, didaticamente, o contexto da formulação de uma política educacional pode se resumir em o contexto de influência em que as disputas dão-se na construção dos discursos que irão definir os princípios gerais da política educacional e, particularmente a política curricular.

O contexto da produção de texto é o momento em que as propostas são oficializadas em documentos e ocorrem as definições dos textos da política curricular. Contudo, não se finaliza a política ao sancionar o texto. A política percorre um longo caminho, uma vez que, os textos são influências que originam consequências para o contexto da prática e esta pode definir a política e chega ao contexto da prática, a arena para a qual a política é endereçada, é neste contexto que me encontro, e que é ponto central deste trabalho.

No contexto da prática os atores principais são os professores, gestores e coordenadores, eles reinterpretam os textos das políticas e assim são produzidos novos discursos em uma circularidade contínua definida por Ball e Bowe (1994) como "ciclo contínuo de políticas".

Para os referidos autores a política está sujeita a recriação que pode mudar significativamente a política original. “Os leitores não são ingênuos, portanto, reinterpretam os 
textos levando em consideração suas experiências e história e as políticas não são implementadas em um processo de verticalização do poder." (BALL \& BOWE, apud MAINARDES, 2006, p. 53)

Ao analisar a maneira como se processa leitura e interpretação dos dispositivos normativos pelos professores aproximamos das práticas pelas quais a escola determina representações de si mesma. O deslocamento, de apropriação e de representação que a instituição de ensino faz, com relação aos textos oficiais não é monótono, já que, a transferência do texto curricular de um contexto para outro se evidencia por um movimento de "recontextualização", por meio do qual se realiza uma escolha e um processo de deslocamento dos acepção teórica em direção à prática.

Segundo Bernstein, "a recontextualização constitui-se a partir da transferência de textos de um contexto a outro, como da academia ao contexto oficial de um Estado nacional, ou do contexto oficial ao escolar" (BERNSTEIN, apud LOPES, 2008, p. 27).

Dessa forma, para atender os objetivos dessa pesquisa e compreender o contexto da prática, realizamos entrevistas semiestruturadas e questionário aberto e fechado com professores que atuam no ProEMI da escola pesquisada, bem como o gestor e a coordenadora pedagógica. O contexto de produção de textos foi acessado por meio de análise documental. Tais como: parecer do CNE/SEB números 5 e 11, Documento Orientador para o PROEMI e a Portaria 971 de 2009 que regulamenta o programa.

A análise dos referidos documentos foi confrontada com as interpretações dos professores no contexto da prática. De tal modo, que ficou evidente que os educadores desempenham papel significativo nas políticas educacionais, o contexto em que estão inseridos com suas particularidades, sua cultura, sua história. Dessa forma, apresentam-se, como agentes de extrema importância no processo de implementação das políticas.

Posto isso, a prática deve ser pensada como parte da política, considerando que os profissionais que atuam nas escolas não são totalmente excluídos dos processos de formulação e implementação de políticas, como salienta Lopes e Macedo (2011). 


\section{CONCLUSÃO}

A pesquisa buscou analisar o Programa Ensino Médio Inovador - PROEMI na proposta indutora de educação integral e sua recontextualização na prática pedagógica em uma Escola Estadual da Bahia .

Ficou evidente que O PROEMI, é fruto da política educacional brasileira que impulsiona o desenvolvimento da educação integral por meio da escola de tempo integral no ensino médio regular, foi instituído em 2009, com o objetivo de fomentar iniciativas curriculares inovadoras nesse nível da educação básica, no sentido de expandir e melhorar a qualidade do ensino que, de acordo com o rendimento nacional, aferido pelo IDEB, mostrava índices abaixo da média.

Neste sentido, a adesão das instituições escolares deveria ser voluntária por meio de suas respectivas secretarias de educação, fortalecendo, assim, a relação dos entes federados em seus diferentes níveis do poder público: federal, estadual, pois o programa instituído pelo MEC dialoga com os sistemas de ensino estaduais responsáveis pela oferta do ensino médio.

Assim, ficou evidente que as políticas passam por um processo até ser efetivamente concretizada. Neste sentido, é importante considerar as influências globais e internacionais no processo de formulação das políticas nacionais. Observando como as ideias são recontextualizadas.

Dessa forma, Ball compreende as políticas como produto de um nexo de influências e interdependências que resultam numa interconexão, e hibridização, isto é, a combinação de lógicas globais, distantes e locais (BALL; BOWE, 1992; BALL, 2006).

\section{REFERÊNCIAS}

BALL, Stephen; BOWE, Richard; GOLD, Annie. Reforming education \& changing school: case studies in policy sociology. Londres - Nova York: Routlegde, 1992.

; MAGUIRE, Meg; BRAUN, Annette. Como as escolas fazem as políticas: atuação em escolas secundárias. Tradução de Janete Bridon. Ponta Grossa: Editora UEPG, 2016.

Educational reform: a critical and post-structural approach. Buckingham: Open University Press, 1994 a.

.Some reflections on policy theory: a brief response to Hatcher and Troyna. Journal of Education Policy, v. 9, n. 2, 1994b.

.Educational reform: a critical and post-structural approach. Buckingham: Open University Press, 1997. 
Cidadania global, consumo e política educacional. In: SILVA, Luiz H. (org.). A escola cidadã no contexto da globalização. Petrópolis: Vozes, 1998.

Diretrizes políticas globais e relações políticas locais em educação. Currículo sem fronteiras, v.1, n.2, 2001. Disponível em< www.curriculosemfronteiras.org $>$. Acesso em 20 out.2016.

Entrevista com Stephen J. Ball: Um diálogo sobre justiça social, pesquisa e política educacional. In: MAINARDES, Jeferson, MARCONDES, Maria Inês. Educação e Sociedade, Campinas, vol. 30, n. 106, p. 303-318,jan./abr. 2009.

Sociologia das políticas educacionais e pesquisa crítico-social: uma revisão pessoal das políticas educacionais e da pesquisa em política educacional. In: BALL, S; MAINARDES, J. (orgs) Políticas educacionais: questões e dilemas. São Paulo: Cortez, 2011.

. Educação global S.A. Novas redes políticas e o imaginário neoliberal. Trad. de Janete Bridon. Ponta Grossa: Editora UEPG, 2014.

BERNSTEIN, Basil. Classes e pedagogia: visível e invisível. Cadernos de Pesquisa, São Paulo, v. 49, p. 26-42, maio. 1984.

A estruturação do discurso pedagógico: classe, códigos e controle. Trad. Tomaz Tadeu da Silva e Luis Fernando Gonçalves Pereira. Petrópolis:Vozes, Vol. IV1996.

BRASIL. Lei $\mathrm{n}^{\circ}$ 9.394, de 20 de dezembro de 1996. Estabelece as diretrizes e bases da educação nacional. Diário Oficial da União, Brasília, 1996.

. MEC/SEB. Reestruturação e Expansão do Ensino Médio no Brasil. Versão preliminar. Brasília, DF, jul,2008. Disponível em:http://portal.mec.gov.br/seb/arquivos/pdf/2009/gt_interministerialresumo2.pf. Acesso em: 01/05/2018.

.Ministério da Educação (MEC). Secretaria de Educação Continuada, Alfabetização e Diversidade (Secad). Programa Mais Educação: gestão intersetorial no território. Brasília, 2009b. Disponível em: http://portal.mec.gov.br/dmdocuments/cader_maiseducacao.pdf.Acesso em: 10.jan.2019

.Ministério da Educação e Cultura - Portaria n 971, de 09 de outubro de 2009 http://portal.mec.gov.br/docman/documentos-pdf/1634-port-971/file Acesso em: 01/05/2018.

Programa Ensino Médio Inovador. Documento Orientador. Brasília: Ministério da Educação, 2014a.

LOPES, Alice Casimiro. Políticas Curriculares: continuidade ou mudança de rumos? In: Revista Brasileira de Educação. n²6. Maio/Jun/Jul/Ago. 2004.

Política de currículo: Recontextualização e Hibridismo. Currículo sem Fronteiras, v.5, n.2. Jul/Dez $2005 . \quad$ Disponível em:

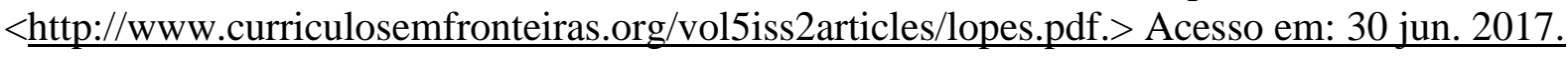

Discursos nas Políticas de Currículo. Currículo sem Fronteiras, Porto Alegre, v.6, n.2, p.33-52, Jul/Dez 2006. 
MAINARDES, Jefferson. Abordagem do ciclo de políticas: uma contribuição para a análise de políticas educacionais. Educação \& Sociedade. V.27, nº 94, p. 47-69, jan/abr. 2006 a Disponível em:<http://www.scielo.br>. Acesso em: 03 de dez.2016

Organização da escolaridade em ciclos no Brasil: revisão da literatura e perspectiva para a pesquisa. Educação e Pesquisa, jan.-abr. 2006, v.32, n.1, pp. 11-30. Disponível em: < http://www.scielo.br>. Acesso em: 03 de set.2017.

Reinterpretando os ciclos de aprendizagem. São Paulo: Cortez, 2007.

A teoria de Basil Bersntein e algumas de suas contribuições para as pesquisas sobre políticas educacionais e curriculares. Revista Teia, v. 11, n. 22, p. 1-24, maio/agosto, 2010.

SAVIANI, Demerval. Educação socialista, pedagogia histórico crítica e os desafios da sociedade de classes. In: SAVIANI, Demerval; LOMBARDI, José Claudinei. Marxismo e educação: debates contemporâneos. Campinas: Autores Associados, 2005, p.223 - 274. 